\title{
Mitigation of pretreatment-derived inhibitors during lignocellulosic ethanol fermentation using spent grain as a nitrogen source
}

\author{
Michael Persson ${ }^{1}$ (D) $\cdot$ Mats Galbe ${ }^{1}$ (D) Ola Wallberg $^{1}$ (i) \\ Received: 4 December 2020 / Revised: 11 March 2021 / Accepted: 23 March 2021 / Published online: 31 March 2021 \\ (C) The Author(s) 2021
}

\begin{abstract}
Nitrogen-containing nutrient sources can be used to mitigate the negative effects of pretreatment-derived inhibitors on product formation rates during bioethanol production. Process economic limitations require these nutrients to be inexpensive. A method of hydrolyzing the protein in the spent grain fraction remaining after wheat grain saccharification, using porcine pancreas trypsin, is presented. This protein hydrolysate was shown to increase the volumetric productivity of ethanol production, measured after 24 $\mathrm{h}$, during fermentation of a lignocellulosic hydrolysate from 0.24 to $0.60 \mathrm{~g} / \mathrm{L} \mathrm{h}$. Although the effects on the productivity, on a per gram basis, were lower than with yeast extract, which increased the product formation rate to $1.64 \mathrm{~g} / \mathrm{L} \mathrm{h}$, amino acid analysis of the soluble polypeptides in the protein hydrolysate showed that the feasibility of using spent grain as a nutrient source could be increased through optimization of the hydrolysis step. Furthermore, it was shown that pretreatment-derived inhibitors could reduce cell growth without affecting ethanol formation rates and that nutrient addition could increase ethanol formation rates without increasing cell growth. Finally, it was shown that the ability of nutrients to affect the product formation rate was limited above a certain inhibitor concentration.
\end{abstract}

Keywords Ethanol $\cdot$ Lignocellulosic biomass $\cdot$ Inhibitors $\cdot$ Nutrients $\cdot$ Spent grains $\cdot$ Saccharomyces cerevisiae

\section{Introduction}

Global warming caused by the combustion of fossil fuels is one of the greatest problems facing us today. Replacing fossil fuels with biofuels in the transport sector would reduce global greenhouse gas emissions. Compared to other technological solutions, such as electric cars and hydrogen fuel cells, biofuels could be rapidly introduced using the existing infrastructure, without the need for massive restructuring of fuel delivery systems or engine technology. One such fuel is bioethanol.

The bioethanol market is well developed, with large quantities already being produced from food crops such as corn, wheat, and sugar cane, referred to as firstgeneration $(1 \mathrm{G})$ bioethanol [1]. However, the production of $1 \mathrm{G}$ bioethanol is controversial, both politically and

Michael Persson

michael.persson@chemeng.lth.se

1 Department of Chemical Engineering, Lund University, Lund, Sweden scientifically, due to its potential to increase food prices as it competes for the same resources [2], and the environmental impact resulting from direct and indirect changes in land use [3]. Attention has therefore been directed towards alternative feedstocks for the production of bioethanol, mainly lignocellulosic biomass in the form of agricultural and forestry waste, as well as dedicated energy crops. Bioethanol produced from these feedstocks is generally referred to as second-generation (2G) bioethanol.

Due to the recalcitrance of $2 \mathrm{G}$ feedstocks, harsher pretreatment methods are required than in $1 \mathrm{G}$ bioethanol production to obtain a fermentable substrate [4]. Various types of hydrothermal pretreatment have been the preferred method in the pretreatment of feedstocks for $2 \mathrm{G}$ bioethanol production [5]. However, compounds such as hydroxymethylfurfural (HMF), furfural, and acetic acid, which are formed during severe hydrothermal pretreatment, can reduce the growth and productivity of yeasts during fermentation [6]. This can have negative effects on the ethanol production cost in several ways. Low productivity increases the capital expenditure as the residence time in the fermentation process is longer, 
thereby increasing the size of equipment required. The toxicity of the pretreatment-derived inhibitors (PDIs) can also affect yeast viability, reducing the total yield of the process, as more substrate is utilized for yeast production to maintain an acceptable productivity [7].

The addition of nitrogen-containing nutrient sources is widely accepted as a method of increasing product formation rates and avoiding slow or arrested fermentation in the production of alcoholic beverages, as well as $1 \mathrm{G}$ fuel ethanol [8-11]. Jørgensen investigated the effect of different nutrient sources on ethanol productivity in the fermentation of a lignocellulosic hydrolysate and found that the addition of a nitrogen source led to significant improvements in the performance, highlighting the importance of nutrient addition for the mitigation of PDIs [12]. Of the nutrients investigated, yeast extract (YE) was found to be the most effective. Furthermore, the effect of YE addition on ethanol productivity was shown to be dependent on the YE concentration. However, the cost of YE would be prohibitive in an industrial setting [11,12], and it is therefore necessary to find alternative low-cost nitrogen sources for $2 \mathrm{G}$ bioethanol production.

One potential source of nitrogen is already available from the $1 \mathrm{G}$ bioethanol industry. The spent grains (SG) remaining after wheat-based bioethanol production is rich in protein and is currently sold as animal feed. The protein in SG is not expected to be usable directly, as polypeptides above a molecular weight of $\sim 10 \mathrm{kDa}$ are not assimilable by yeast [9]. However, it has been shown that proteases can be used to break down wheat proteins into compounds that are assimilable by yeast [10]. This would be especially attractive as a strategy for improving the performance of fermentation in integrated $1 \mathrm{G}$ and $2 \mathrm{G}$ ethanol processes, which have shown promise as an alternative to traditional standalone $1 \mathrm{G}$ and $2 \mathrm{G}$ ethanol plants $[13,14]$, since the SG would be readily available onsite.

While the research by Jørgensen has shed some light on how nutrients can be utilized to mitigate the effects of inhibitors, the effects of nutrients, inhibitors, yeast loadings, and their interactions have not been fully explored. Aspects of the fermentation process, such as the way in which they affect the rate of product formation, the dynamics of cell growth, and the mechanisms by which assimilable nitrogen facilitates inhibitor mitigation, are still not fully understood.

The main aim of this study was to investigate the use of hydrolyzed wheat protein from SG as a source of nutrients to mitigate the negative effects of PDIs on ethanol productivity during the fermentation of a lignocellulosic hydrolysate. The second aim was to elucidate the way in which nitrogen sources increase ethanol productivity during this kind of fermentation. The results presented in this paper could help guide industrial ethanol producers when choosing strategies for dealing with PDIs during fermentation.

\section{Materials and methods}

\subsection{Material preparation}

\subsubsection{Wheat straw and wheat grain mixture}

Winter wheat straw was collected near Køge, Denmark. The straw was air-dried to a moisture content below $10 \%$ before being chopped into $5-10-\mathrm{cm}$ pieces, and stored at room temperature before pretreatment. A grain meal mixture consisting of $90 \%$ wheat, $5 \%$ triticale, and $5 \%$ barley was kindly provided by Lantmännen Agroetanol, Norrköping, Sweden.

\subsubsection{Saccharified wheat grain}

The grain mixture was saccharified in a 2-step hydrolysis process consisting of a liquefaction and a saccharification step. Both steps were performed in a 20-L evaporator (Rotavapor ${ }^{\circledR}$ R-153; Büchi Laborteknik AG, Flawil, Switzerland). Before hydrolysis, the grain mixture was mixed with water to achieve a dry matter (DM) content of $\sim 25 \%$. Liquefaction was initiated by supplementing the grain slurry with $0.5 \mathrm{~mL} * \mathrm{~kg}$ dry matter of Bacillus licheniformis $\alpha$-amylase (Sigma-Aldrich, Denmark), after which the liquefaction step was performed at $90{ }^{\circ} \mathrm{C}$ and $\mathrm{pH} 5.5$ for $3 \mathrm{~h}$. Saccharification was initiated by the addition of $1 \mathrm{~mL} / \mathrm{kg}$ dry matter of Aspergillus niger amyloglucosidase (Sigma-Aldrich, Denmark), which had an activity of $260 \mathrm{U} / \mathrm{mL}$, and the saccharification step was performed at $60{ }^{\circ} \mathrm{C}$ and $\mathrm{pH} 5$ for $24 \mathrm{~h}$. The saccharified wheat grain was frozen and stored until use.

\subsubsection{Spent grain}

To obtain the SG fraction, the saccharified wheat grain was centrifuged, and the supernatant was removed to obtain the insoluble solid fraction. The solids were then resuspended in deionized water, centrifuged, and decanted to minimize the amount of residual soluble glucose in the SG. This procedure was carried out 5 times. The SG was then dried in a convection oven at $70{ }^{\circ} \mathrm{C}$ for $24 \mathrm{~h}$.

\subsubsection{Wheat protein hydrolysate}

In order to make the nitrogen in the SG assimilable by yeast, it was subjected to enzymatic proteolysis using porcine pancreas trypsin (Sigma-Aldrich, USA). Dried SG was first milled using a coffee grinder. The milled SG was mixed with deionized water at a dry matter content of $5 \% \mathrm{w} / \mathrm{w}$, and the $\mathrm{pH}$ was adjusted to 8 using $\mathrm{NaOH}(50 \% \mathrm{w} / \mathrm{w})$. Trypsin was added at a trypsin to SG mass ratio of 1:20, according to the procedure described by the manufacturer. Hydrolysis was carried out in an incubator at $47^{\circ} \mathrm{C}$ for $60 \mathrm{~min}$, after which the $\mathrm{pH}$ was measured in the wheat protein hydrolysate (WPH) and found 
to be 6.4. The WPH was dried in a convection oven at $70{ }^{\circ} \mathrm{C}$ for $24 \mathrm{~h}$ to prevent infection. The dried WPH was stored in the convection oven at $45{ }^{\circ} \mathrm{C}$ until use.

\subsubsection{Pretreated wheat straw}

The wheat straw was soaked overnight in an aqueous solution of $0.2 \% \mathrm{H}_{2} \mathrm{SO}_{4}$ at a solid to liquid ratio of 1:20. After soaking, the straw was pressed in a 25-L filter press (Tinkturenpressen HP25M, Fischer Maschinenfabrik GmbH, Germany) to a dry matter content of $44 \%$. The wheat straw was then steampretreated using saturated steam at $190{ }^{\circ} \mathrm{C}$ for $10 \mathrm{~min}$ in a 10-L reactor (Process \& Industriteknik AB, Sweden), as described previously [15]. The steam pretreatment conditions were chosen based on previous optimization of the conditions for the pretreatment of wheat straw [16]. The pretreated wheat straw was stored in sealed buckets at $4{ }^{\circ} \mathrm{C}$ until use.

\subsubsection{Hydrolyzed wheat straw}

To obtain a lignocellulosic hydrolysate for the fermentation experiments, enzymatic hydrolysis was performed on pretreated wheat straw using Cellic Ctec 2 (Novozymes A/S, Denmark). Hydrolysis was carried out in a 60-L, jacketed, stainless-steel stirred vessel for $72 \mathrm{~h}$ at $50{ }^{\circ} \mathrm{C}$. $\mathrm{NaOH}(50 \%$ $\mathrm{w} / \mathrm{w}$ ) was used to maintain the $\mathrm{pH}$ at 5 during hydrolysis. An enzyme loading of $15 \mathrm{FPU} / \mathrm{g}$ glucan was used. After hydrolysis, the hydrolysate was pressed through a nylon filter using the 25-L filter press described above to separate the liquid hydrolysate from residual solids. The hydrolysate liquid was frozen and stored until use.

\subsection{Experimental design}

Two series of fermentation experiments were carried out with hydrolyzed wheat straw (HWS) as the substrate. The purpose of the first series was to determine how the product formation rate was affected by initial cell mass and inhibitor concentration. The first series consisted of a 2-factor, 3-level full factorial experiment with 3 center point replicates, as specified in Table 1 . The two factors investigated during the first series of experiments were hydrolysate loading, representing inhibitor level, and yeast loading. Fermentation was carried out in serum flasks with a working mass of $50 \mathrm{~g}$. $\mathrm{KH}_{2} \mathrm{PO}_{4}(0.025 \mathrm{~g} / \mathrm{kg})$ and $\mathrm{MgSO}_{4}(0.025 \mathrm{~g} / \mathrm{kg})$ were added to the broth, and citrate was added to a concentration of $50 \mathrm{mM}$ to maintain $\mathrm{pH} 5$ during fermentation. Ethanol Red yeast (Lesaffre, France) was used in all experiments. Before inoculation, the dry yeast was activated with deionized water, at 5 times the solid weight of the yeast, and incubated at $35{ }^{\circ} \mathrm{C}$ for approximately $30 \mathrm{~min}$. To remove the carbohydrate substrate
Table 1 Experimental design of the first series of fermentation experiments, in terms of hydrolysate and yeast loading

\begin{tabular}{lll}
\hline Condition & Hydrolysate loading (\% mass) & Yeast loading $(\mathrm{g} / \mathrm{kg})$ \\
\hline 1 & 25 & 0.5 \\
2 & 25 & 1.5 \\
3 & 25 & 2.5 \\
4 & 50 & 0.5 \\
5 & 50 & 1.5 \\
6 & 50 & 2.5 \\
7 & 75 & 0.5 \\
8 & 75 & 1.5 \\
9 & 75 & 2.5 \\
10 & 50 & 1.5 \\
11 & 50 & 1.5 \\
\hline
\end{tabular}

concentration as a factor affecting the growth rate and product formation rate, all samples were supplemented with glucose to a concentration of $85 \mathrm{~g} / \mathrm{kg}$ broth. Fermentation was carried out in an incubator at $35{ }^{\circ} \mathrm{C}$ for $96 \mathrm{~h}$. The results from this series of experiments were evaluated by fitting the data from cell counting and measured fermentation rates to quadratic response surface models using multiple linear regression. When selecting factors for the model main factors, first-order interaction and quadratic terms were considered. Factors that were not significant were rejected during model selection.

The purpose of the second series of the fermentation experiments was to investigate whether WPH could be used to boost product formation rates in the presence of inhibitory compounds. This was done by performing a series of fermentation experiments with varying amounts of WPH. Fermentation was also carried out with YE (Thermo Fisher Scientific, Germany) as a nitrogen source, in parallel, as a standard for comparison. Based on the results obtained from the first experimental series, two different conditions were chosen for the second series of fermentation experiments. These were conditions 1 and 9 in Table 1, which are referred to as mild (1) and harsh (9). These conditions were chosen as they showed consistent ethanol production, while still having the potential for improved ethanol formation rates. Fermentation was carried out in the same manner as described above for the series 1. The nitrogen sources used in these experiments were added to the serum flasks as dried powder on a mass basis. Additional fermentation experiments were carried out without the addition of a nitrogen source to provide a reference. All fermentation experiments were carried out in duplicate. The experimental conditions are given in Table 2. 
Table 2 Experimental conditions in the second experimental series. WPH and YE denote the dry matter loading of the wheat protein hydrolysate and yeast extract. The mild fermentation condition was $25 \%$ hydrolysate and $0.5 \mathrm{~g} / \mathrm{kg}$ yeast loading, and the harsh fermentation condition was $75 \%$ hydrolysate and $2.5 \mathrm{~g} / \mathrm{kg}$ yeast loading. Ref. 1 and Ref. 2 are reference experiments without any nutrient addition

\begin{tabular}{llll}
\hline Condition & WPH $(\mathrm{g} \mathrm{DM} / \mathrm{kg})$ & $\mathrm{YE}(\mathrm{g} \mathrm{DM} / \mathrm{kg})$ & Fermentation condition \\
\hline Ref. 1 & 0 & 0 & Mild \\
1 & 1 & 0 & Mild \\
2 & 4 & 0 & Mild \\
3 & 7 & 0 & Mild \\
4 & 0 & 1 & Mild \\
5 & 0 & 4 & Mild \\
6 & 0 & 7 & Mild \\
Ref. 2 & 0 & 0 & Harsh \\
7 & 1 & 0 & Harsh \\
8 & 4 & 0 & Harsh \\
9 & 7 & 0 & Harsh \\
10 & 0 & 1 & Harsh \\
11 & 0 & 4 & Harsh \\
12 & 0 & 7 & Harsh \\
\hline
\end{tabular}

\subsection{Analytical methods}

\subsubsection{Carbohydrates and inhibitors}

The carbohydrate content of the HWS was determined using high-performance liquid chromatography (HPLC) with a refractive index detector (RID-10A, Shimadzu, Japan) and a Coregel CHO782 (Concise Separations, San Jose, CA, USA) column for separation. A temperature of $70{ }^{\circ} \mathrm{C}$ was maintained throughout separation. Isocratic elution was performed at a flow rate of $0.6 \mathrm{~mL} / \mathrm{min}$, using DI water as eluent. The concentrations of the inhibitory compounds furfural, $\mathrm{HMF}$, and acetic acid in the HWS were determined with HPLC using the same kind of refractive index detector (RID-10A) and an Aminex HPX-87H (Biorad, Hercules, CA, USA) column for separation. A temperature of $50{ }^{\circ} \mathrm{C}$ was maintained throughout separation. Isocratic elution was performed at a flow rate of $0.5 \mathrm{~mL} / \mathrm{min}$, using $0.005 \mathrm{M} \mathrm{H}_{2} \mathrm{SO}_{4}$ as eluent. The concentrations of carbohydrates and inhibitors in the HWS are given in Table 3.

\subsubsection{Nutrient amino acid sample preparation}

A known quantity of nutrient sample, dried at $45^{\circ} \mathrm{C}$ in the convection oven, was resuspended in deionized water to determine the amount of free amino acids and polypeptides present in the WPH and YE. The resuspended nutrient solutions were vortexed to ensure solubilization of all the soluble components in the nutrient source. After vortexing, the samples
Table 3 Composition of soluble carbohydrates and known inhibitors in the HWS. Error estimation represents standard deviation

\begin{tabular}{ll}
\hline Component & Concentration $(\mathrm{g} / \mathrm{L})$ \\
\hline Sugars & \\
Glucose & $84.9 \pm 0.8$ \\
Xylose & $32.5 \pm 0.7$ \\
Galactose & $3.1 \pm 0.6$ \\
Arabinose & $3.9 \pm 0.1$ \\
Mannose & $1.6 \pm 0.4$ \\
Inhibitors & \\
Acetic acid & $6.0 \pm 0.6$ \\
Furfural & $0.8 \pm 0.1$ \\
HMF & $0.5 \pm 0.1$ \\
\hline
\end{tabular}

were filtered using $0.2-\mu \mathrm{m}$ nylon syringe filters to remove any insoluble components. The filtered solution was diluted and then directly analyzed according to the amino acid analysis procedure described in Section 2.3.3; analysis was performed in duplicate. In order to determine the polypeptide content in the nutrient samples, the filtered samples were first subjected to acid hydrolysis to break the peptide bonds. The filtered liquid samples were then added to a pressure tube, and $37 \%$ $\mathrm{HCl}$ was added until a concentration of $6 \mathrm{M} \mathrm{HCl}$ was obtained in the pressure tube. Nitrogen gas was sparged through the sample for 2 min to remove any dissolved oxygen from the system. The pressure tubes were then immediately sealed to maintain the nitrogen atmosphere. The pressure tubes were then placed in a convection oven at $110{ }^{\circ} \mathrm{C}$ for $24 \mathrm{~h}$, after which the samples were removed from the oven and allowed to cool to room temperature. The samples were neutralized using $50 \% \mathrm{w} / \mathrm{w} \mathrm{NaOH}$ solution, and diluted and analyzed according to the amino acid analysis procedure. This method for protein sample preparation was based on methods presented in a previous study [17]. Sample preparation for polypeptide analysis was performed in duplicate for each nutrient.

\subsubsection{Amino acid analysis}

The amino acid content in the samples was determined using an ICS-5000+ ion-exchange chromatography system (Dionex, Thermo Fisher Scientific, USA). An AminoPac10 column system consisting of a guard column $(50 \mathrm{~mm} \times$ $2 \mathrm{~mm}$ I.D. $)$ and an analytical column $(250 \mathrm{~mm} \times 2 \mathrm{~mm}$ I.D. $)$ was used for separation of the amino acids. An amperometric cell with a gold electrode and a $\mathrm{AgCl}$ reference electrode was used for detection. A temperature of $30{ }^{\circ} \mathrm{C}$ was maintained throughout separation. Gradient elution was performed at a flow rate of $0.25 \mathrm{~mL} / \mathrm{min}$, with mobile phases of water, $0.25 \mathrm{M}$ sodium hydroxide, and $1 \mathrm{M}$ sodium acetate, using a gradient method recommended for protein hydrolysates known to contain tryptophan, according to the AAA-Direct system product manual. 


\subsubsection{Fermentation rates}

The fermentation rates during the experiments were analyzed gravimetrically by determining the mass loss due to carbon dioxide production. Based on the glucose available in the samples, the maximum $\mathrm{CO}_{2}$ evolution for all samples was $2.08 \mathrm{~g}$. The total mass of each sample was measured at the start of the experiment. The samples were then weighed on an analytical scale after $1,2,4,8,12,24,48,72$, and $96 \mathrm{~h}$. To verify that the mass loss during fermentation was the result of ethanol production, liquid samples were taken from the broth after the experiment had been terminated. The samples were passed through a $0.2-\mu \mathrm{m}$ nylon syringe filter and frozen until analysis. The ethanol concentration was determined using HPLC with a refractive index detector and an Aminex HPX$87 \mathrm{H}$ column for separation.

\subsubsection{Cell counting}

Liquid samples were taken from the fermenters after 96 $\mathrm{h}$, diluted with deionized water, and then dyed with methylene blue to determine cell viability. Viability was only determined in samples from the second experimental series. (Cell counting results from series 1 only reflect the total cell count.) Cell counting was performed manually using a microscope with a hemacytometer (LO-Labortoptik Ltd., UK).

\section{Results}

\subsection{Fermentation with nutrient addition}

Adding WPH during fermentation under the mild condition had a positive effect on the ethanol formation rate, as can be seen in Fig. 1a, where the volumetric productivity after $24 \mathrm{~h}$ increased from $0.24 \mathrm{~g} / \mathrm{L} \mathrm{h}$ (no nutrient addition) to $0.60 \mathrm{~g} / \mathrm{L} \mathrm{h}$ ( $7 \mathrm{~g} / \mathrm{kg} \mathrm{WPH}$ ). Furthermore, this effect appeared to be concentration dependent. However, no significant improvement in the volumetric productivity was observed above a WPH addition of $4 \mathrm{~g} / \mathrm{kg}$.

The addition of YE had a greater effect on the fermentation rate at the mild condition than WPH, as can be seen in Fig. 1b, with a volumetric productivity of $1.64 \mathrm{~g} / \mathrm{L} \mathrm{h}$ after $24 \mathrm{~h}$. This observation is in line with a previous study in which the effects of different nutrient sources on the fermentation of a lignocellulosic hydrolysate were compared [12]. In that study, YE had the greatest impact on the product formation rates of all the nutrient sources investigated. Although WPH exhibited a saturation effect above the addition of $4 \mathrm{~g} / \mathrm{kg}$, a clear increase in the ethanol formation rate was seen with YE $12 \mathrm{~h}$ into the fermentation, which was the last measurement before glucose depletion.
It can be seen from Fig. 1c and d that nutrient addition under the harsh condition had almost no impact on the ethanol formation rate for the first $72 \mathrm{~h}$ of fermentation, with either WPH or YE. However, after $72 \mathrm{~h}$, the ethanol formation rate with YE showed a clear concentration-dependent effect. This indicates that the inhibitor mitigating effect of nutrients cannot be taken advantage of by the yeast above a certain inhibitor concentration. Results from HPLC analysis of the final ethanol concentration in the fermentation broth can be seen in Figure S1. The figure shows a good agreement between the numbers calculated for ethanol production based on $\mathrm{CO}_{2}$ evolution and HPLC analysis.

Three main observations were made based on the cell counting data. Firstly, at low inhibitor concentrations, both nutrients had a concentration-dependent effect on yeast growth. This can be seen in Fig. $2 a$ and b, which show increasing total cell count with increasing concentration of the added nutrient. However, it can be seen from Fig. $2 \mathrm{a}$ that this correlation was not linear with WPH. The addition of WPH appeared to have no effect on the cell growth at lower concentrations but resulted in a dramatic increase in cell growth when $7 \mathrm{~g} / \mathrm{kg}$ was added. It should, however, be noted that this increase in cell count did not appear to have an impact on the rate of ethanol formation (as can be seen in Fig. 1a). Secondly, at high inhibitor concentrations, the addition of nutrients had a little effect on cell growth, as can be clearly seen in Fig. 2c and $\mathrm{d}$, where the total cell count remained almost unchanged between the beginning and end of the experiments. Thirdly, the total viable cell count decreased between the beginning and end of the experiment in all cases under the harsh condition, showing that with this high inhibitor loading the rate of cell death was greater than the cell growth rate.

\subsection{Nutrient analysis}

In order to explain the different behavior in fermentation observed when adding YE or WPH, the free amino acid composition was measured in both nutrient sources. The results of this analysis are given in Table 4. The main difference between the two nutrient sources was related to the presence or absence of specific amino acids in the solution. While 17 different types of amino acids were observed as free amino acids in YE, only 9 were detected in WPH. Furthermore, when comparing the total amount of free amino acids available in the nutrient sources, it was found that approximately $26 \%$ of YE dry mass was composed of free amino acids while only $11 \%$ of WPH dry mass was made up of free amino acids. The results of the polypeptide analysis showed that a higher amount of amino acids was still bound in protein and polypeptides in WPH (44\%) than in YE $(27 \%)$. It should be noted that, as yeast has been shown to assimilate polypeptides with molecular weights up to at least $1 \mathrm{kDa}$ [9], some of the polypeptide content in WPH and YE could have been assimilated 

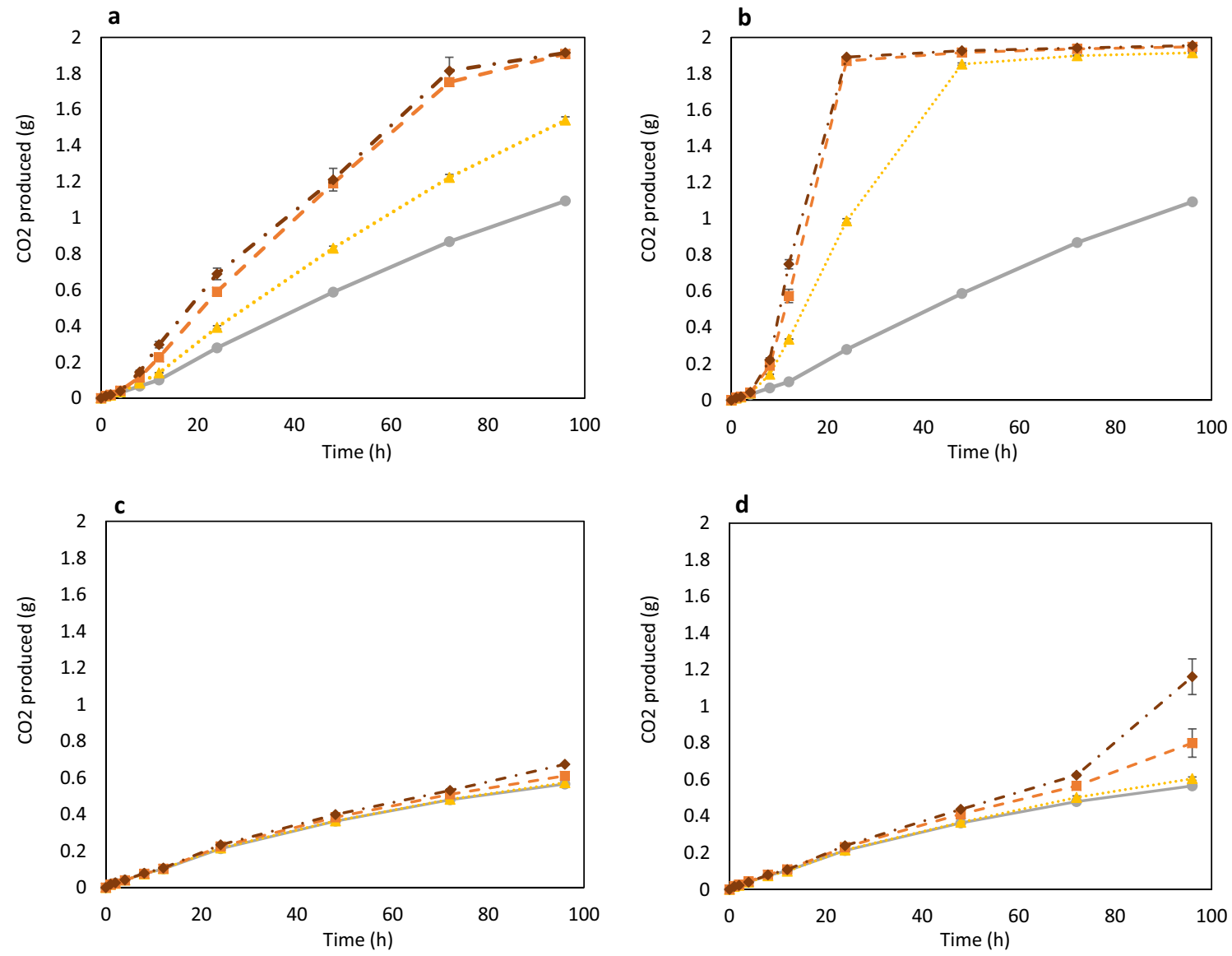

Fig. 1 Carbon dioxide evolution during fermentation with nutrient addition $(0 \mathrm{~g} / \mathrm{kg}$ reference case [circle], $1 \mathrm{~g} / \mathrm{kg}$ [up-pointing triangle], 4 $\mathrm{g} / \mathrm{kg}$ [square], $7 \mathrm{~g} / \mathrm{kg}$ [diamond]). a WPH under mild condition. b YE

under mild condition. $\mathbf{c}$ WPH under harsh condition. d YE under harsh condition

by the yeast during fermentation, and thus contributed to the fermentation dynamics. However, the extent to which this occurred is unknown as the molecular weight of the polypeptide fraction was not measured in this study.

\subsection{Yeast loading vs. inhibitor loading}

Response surface models for net cell growth (calculated as the difference between the initial cell count and the final cell count) and volumetric productivity after $24 \mathrm{~h}$ were chosen based on goodness of fit and residual of regression analysis. The following models were selected:

Net cell growth:

$Y_{\text {growth }}=\alpha_{1}+\alpha_{2}\left[X_{\mathrm{HWS}}\right]$

Volumetric productivity $(24 \mathrm{~h})$ :

$$
\begin{aligned}
Y_{\text {prod }}= & \beta_{1}+\beta_{2}\left[X_{\text {yeast }}\right]+\beta_{3}\left[X_{\mathrm{HWS}}\right] \\
& +\beta_{4}\left[X_{\text {yeast }}\right]\left[X_{\mathrm{HWS}}\right]+\beta_{5}\left[X_{\mathrm{HWS}}\right]^{2}
\end{aligned}
$$

where $Y_{\text {growth }}$ is the net cell growth $(\mathrm{g}), Y_{\text {prod }}$ is the volumetric productivity after $24 \mathrm{~h}(\mathrm{~g} / \mathrm{L} \mathrm{h}), X_{\text {yeast }}$ is the

yeast loading $(\mathrm{g} / \mathrm{kg}), X_{\mathrm{HWS}}$ is the loading of HWS (\%), and $\alpha_{1}-\alpha_{2}$ and $\beta_{1}-\beta_{5}$ represent factor coefficients. The coefficient values for the models, their corresponding $t$ statistics and $p$ values, and the coefficient of determination for the models are given in Table 5. The values of the coefficients are based on linear regression using coded variables. This means that the coefficients represent the relative effect of each factor in the respective models within the range of factor values investigated.

The main observation made regarding the effect of yeast loading and inhibitor concentration was the appearance of two modes of inhibition. Increasing the level of PDIs during fermentation had a direct effect on the growth of yeast cells. As can be seen in Fig. 3, the difference between the initial and final cell counts decreased as the level of HWS was increased, indicating a direct inhibitory effect on cell growth, regardless of inhibitor concentration. This was further supported by the results from the model regression as presented in Table 5, as the only significant factor in the net cell growth model was the negative linear effect of HWS loading.

In contrast to the findings regarding the cell count, the $\mathrm{CO}_{2}$ evolution rate did not show the same kind of 

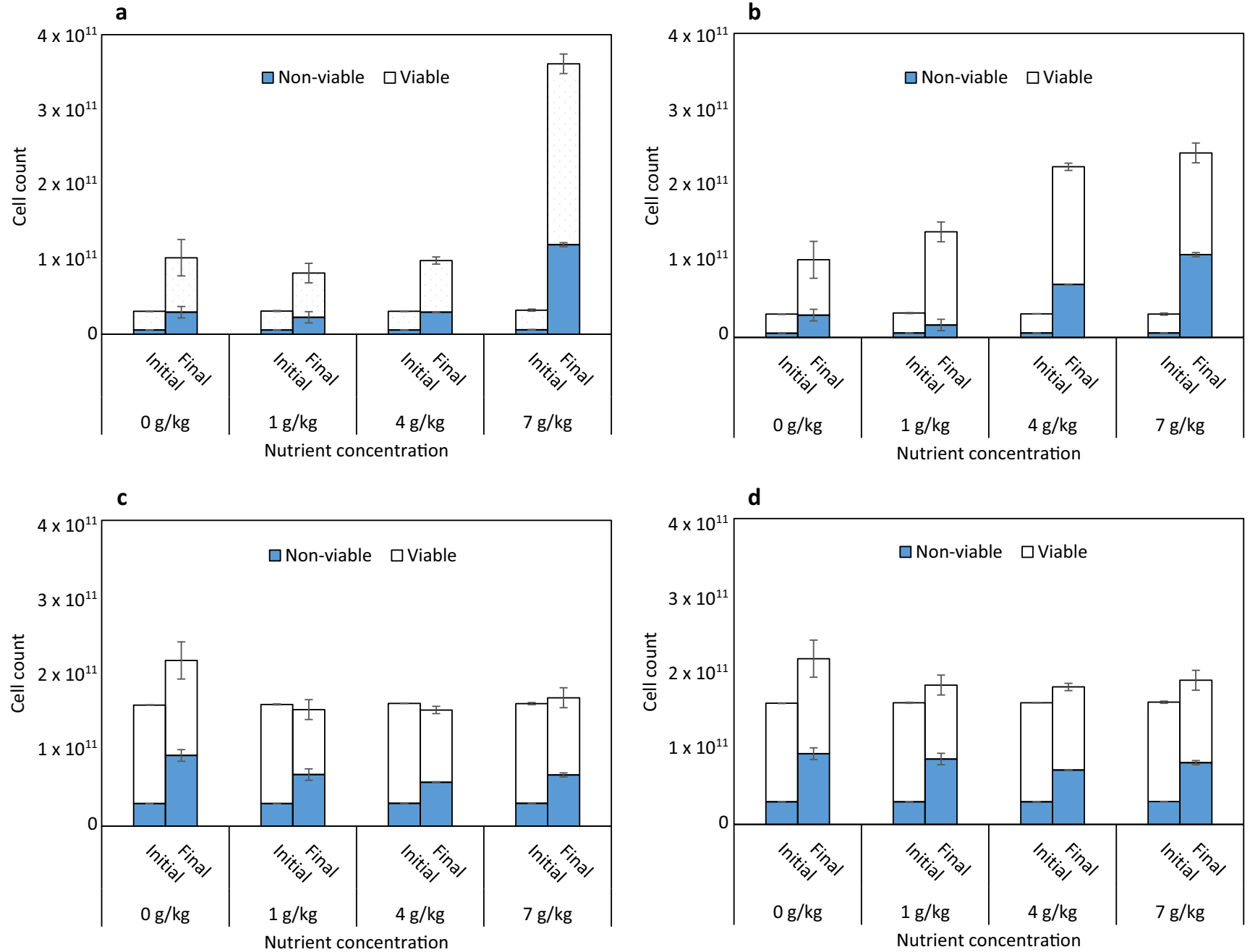

Fig. 2 Cell counts of non-viable and viable cells during fermentation with added nutrients $(0 \mathrm{~g} / \mathrm{kg}$ reference case, $1 \mathrm{~g} / \mathrm{kg}, 4 \mathrm{~g} / \mathrm{kg}, 7 \mathrm{~g} / \mathrm{kg})$. Initial refers to the cell count at the start of fermentation, and Final to the cell count after 96 h. a WPH under mild condition. b YE under mild

correlation with the HWS level. As can be seen in Fig. 4 , at any given initial yeast concentration, the ethanol formation rate was unaffected at the $25 \%$ and $50 \%$ hydrolysate loadings. However, at $75 \%$ hydrolysate, a significant decrease in the rate of ethanol formation was observed, regardless of the initial yeast loading. In the quadratic regression model, this is supported by the existence of a significant negative quadratic effect from HWS loading, as seen in Table 5. Comparing this observation with the cell counting data clearly indicates that the addition of a complex mixture of lignocellulosic inhibitors does not affect the metabolic pathways in yeast regulating ethanol formation and cell growth in the same way. It also shows that within a certain range of inhibitor concentration, yeast can maintain an almost unaffected ethanol formation rate, even when cell growth is inhibited.

condition. $\mathbf{c}$ WPH under harsh condition. d YE under harsh condition. Error bars show the range of the results from the duplicate fermentation experiments

\section{Discussion}

The rate of product formation by a microorganism can be divided into two parts, as proposed by Luedeking-Piret [18]. One is associated with the energy required for growth, and the other with the energy required for other cell functions, i.e., maintenance, as described by Eq. 1:

$\frac{d P}{d t}=\alpha \frac{d X}{d t}+\beta X$

where $P(\mathrm{~g} / \mathrm{L})$ denotes the product concentration, $t(\mathrm{~h})$ time, $X$ $(\mathrm{g} / \mathrm{L})$ cell concentration, $\alpha(\mathrm{g} / \mathrm{g})$ a constant representing growth-associated product formation, and $\beta(\mathrm{g} / \mathrm{g} \mathrm{h})$ a constant representing nongrowth-associated product formation. The relationship between ethanol formation and energy production in the cell comes from the fact that in the case of anaerobic catabolism of glucose to ethanol, the result is a net production 
Table 4 Free amino acid composition and amino acid composition of polypeptides in YE and WPH. Error estimation represents range based on duplicate samples

\begin{tabular}{|c|c|c|c|c|}
\hline \multirow[t]{2}{*}{ Amino acids } & \multicolumn{2}{|l|}{ WPH } & \multicolumn{2}{|l|}{ YE } \\
\hline & $\begin{array}{l}\text { Free amino acids (dry } \\
\text { mass } \% \text { ) }\end{array}$ & $\begin{array}{l}\text { Polypeptides (dry } \\
\text { mass \%) }\end{array}$ & $\begin{array}{l}\text { Free amino acids (dry } \\
\text { mass \%) }\end{array}$ & $\begin{array}{l}\text { Polypeptides } \\
\text { (dry mass } \\
\%)\end{array}$ \\
\hline L-Arginine & $0.87 \pm 0.18$ & $5.52 \pm 0.18$ & $2.09 \pm 0.01$ & $2.89 \pm 0.07$ \\
\hline L-Lysine & $0.06 \pm 0.01$ & $6.00 \pm 0.00$ & $0.79 \pm 0.02$ & $4.99 \pm 0.41$ \\
\hline L-Alanine & $2.15 \pm 0.16$ & $1.18 \pm 0.03$ & $2.29 \pm 0.37$ & $1.23 \pm 0.08$ \\
\hline L-Threonine & n.d.* & $2.87 \pm 0.01$ & $0.97 \pm 0.20$ & $1.81 \pm 0.03$ \\
\hline Glycine & $0.05 \pm 0.01$ & $2.70 \pm 0.01$ & $0.59 \pm 0.01$ & $1.90 \pm 0.02$ \\
\hline L-Valine & n.d.* & $3.75 \pm 0.03$ & $1.92 \pm 0.00$ & $1.44 \pm 0.02$ \\
\hline L-Serine & n.d.* & $2.60 \pm 0.01$ & $1.51 \pm 0.02$ & $1.13 \pm 0.00$ \\
\hline L-Proline & $0.04 \pm 0.04$ & $2.04 \pm 0.01$ & $0.41 \pm 0.04$ & $1.47 \pm 0.02$ \\
\hline L-Isoleucine & $7.58 \pm 0.01$ & n.d.* & $1.58 \pm 0.02$ & $1.32 \pm 0.01$ \\
\hline L-Leucine & $0.10 \pm 0.01$ & $4.25 \pm 0.00$ & $2.85 \pm 0.06$ & $1.16 \pm 0.15$ \\
\hline L-Methionine & n.d.* & $0.07 \pm 0.05$ & $0.38 \pm 0.24$ & n.d.* \\
\hline L-Histidine & n.d.* & $0.88 \pm 0.00$ & $0.07 \pm 0.07$ & $1.20 \pm 0.00$ \\
\hline L-Phenylalanine & n.d.* & $2.87 \pm 0.02$ & $1.99 \pm 0.13$ & $1.03 \pm 0.04$ \\
\hline L-Glutamic acid & $0.41 \pm 0.06$ & $7.80 \pm 0.42$ & $5.73 \pm 0.28$ & n.d.* \\
\hline L-Aspartic acid & n.d.* & n.d.* & $1.60 \pm 0.05$ & $4.18 \pm 0.05$ \\
\hline L-Cysteine & n.d.* & n.d.* & n.d.* & $0.02 \pm 0.01$ \\
\hline L-Tyrosine & n.d.* & $1.54 \pm 0.07$ & $0.77 \pm 0.38$ & $1.04 \pm 0.05$ \\
\hline L-Tryptophan & $0.10 \pm 0.3$ & n.d.* & $0.57 \pm 0.14$ & n.d. \\
\hline
\end{tabular}

*Not detected

of ATP [19]. This relationship between growth, maintenance, and product formation rate will be used as a basis for the discussion.

Upon comparing the effect of adding WPH and YE during fermentation, it is clear that YE is superior in increasing the product formation rate on a weight basis. This can probably be explained by differences in the assimilable nitrogen content of WPH and YE. It has been suggested previously that the addition of a complex mixture of amino acids, even one that does not contain all the components necessary for growth, is expected to lead to an increased growth rate and product formation rate compared to the addition of a single amino acid [8,

Table 5 Coefficients and statistics for quadratic response surface models developed for yeast and inhibitor loading experiments

\begin{tabular}{llllll}
\hline Model & $R^{2}$ & & Coefficients & $t$ test & $p$ values \\
\hline$Y_{\text {growth }}$ & \multirow{2}{*}{0.73} & $\alpha_{1}$ & 0.0316 & 4.47 & 0.002 \\
& & $\alpha_{2}$ & -0.0470 & 4.91 & 0.001 \\
$Y_{\text {prod }}$ & \multirow{2}{*}{0.98} & $\beta_{1}$ & 0.658 & 20.2 & 0.000 \\
& & $\beta_{2}$ & 0.326 & 10.9 & 0.000 \\
& & $\beta_{3}$ & -0.298 & 9.98 & 0.000 \\
& & $\beta_{4}$ & -0.194 & 5.30 & 0.002 \\
& & $\beta_{5}$ & -0.247 & 5.58 & 0.001 \\
\hline
\end{tabular}

$10,20,21]$. As seen from the analysis of the amino acid composition of the nutrients, the fact that the total concentration of free amino acids in YE was more than twice that in WPH indicates that fermentation would be less limited by nutrient availability in the YE case. Furthermore, the higher diversity of free amino acids observed in YE indicates that more amino acids could be assimilated directly instead of requiring deamination and resynthesis to achieve the correct amino acid composition for protein production. Removing the need for these additional synthesis steps would remove the bottlenecks caused by these synthesis pathways [20]. Thus, YE would be expected to contribute to a higher growth rate and, as described by Eq. 3, a higher product formation rate.

Although YE outperformed WPH during fermentation in the present study with regard to improving product formation rates, WPH still shows promise as a potential commercial nutrient source. The findings from the quantitative hydrolysis of soluble protein in WPH showed that a greater diversity of amino acids was still bound as proteins and polypeptides, and further optimization of the protease hydrolysis procedure could possibly release more of this nutrient's potential. For example, using a combination of proteases with different types of proteolytic activity could result in a nutrient source with a higher amount and more diverse composition of assimilable nitrogen. Furthermore, if this approach were to be 
Fig. 3 Total cell count in fermentation experiments investigating the effects of yeast loading and HWS loading. Initial refers to the cell count at the start of fermentation, and Final to the cell count after 96 h. $25 \%, 50 \%$, and $75 \%$ hydrolysate denote the $\%$ mass of HWS in the

fermentation. The numbers 1-9 refer to the conditions in Table 1 . Sample 5 shows the average of the center point replicates. Error bars represent the standard deviation based on three center point replicates

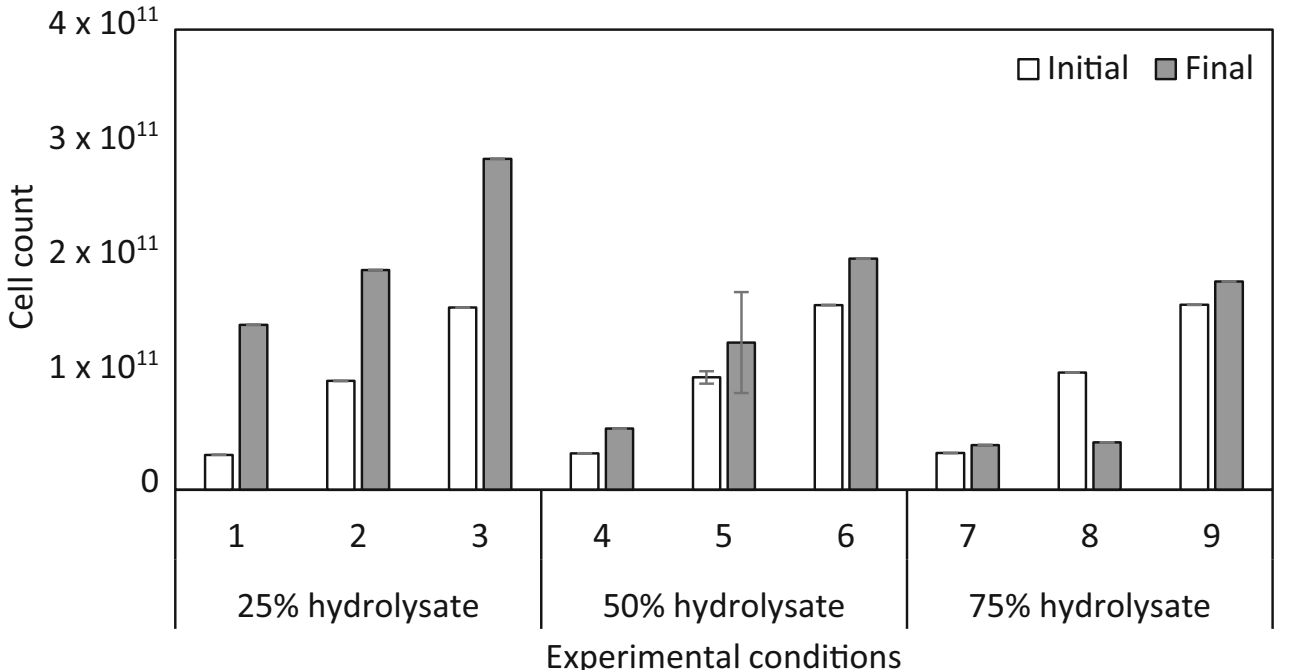

adopted in an integrated $1 \mathrm{G}$ and $2 \mathrm{G}$ ethanol plant in the manner suggested previously [14, 18, 22], proteolytic hydrolysis could potentially be implemented directly in the saccharification stage of the $1 \mathrm{G}$ part of the process. This could mitigate the problems of low product formation rates caused by PDIs, without any significant increase in the total investment cost.
In this study, several observations were made with regard to the effect of nutrients and PDIs on growth-associated and nongrowth-associated product formation. The first observation was based on the results of the experiments investigating yeast and inhibitor loading. Taking Eq. 3 into account, the observation that ethanol production was unaffected while cell growth was decreased at moderate levels of PDIs indicates
Fig. 4 Carbon dioxide evolution during fermentation experiments to investigate the effects of yeast loading and $\%$ mass HWS in the fermentation ( $25 \%$ hydrolysate [circle], $50 \%$ hydrolysate [square], 75\% hydrolysate [uppointing triangle]). a $0.5 \mathrm{~g} / \mathrm{kg}$ yeast loading. b $1.5 \mathrm{~g} / \mathrm{kg}$ yeast loading. c $2.5 \mathrm{~g} / \mathrm{kg}$ yeast loading

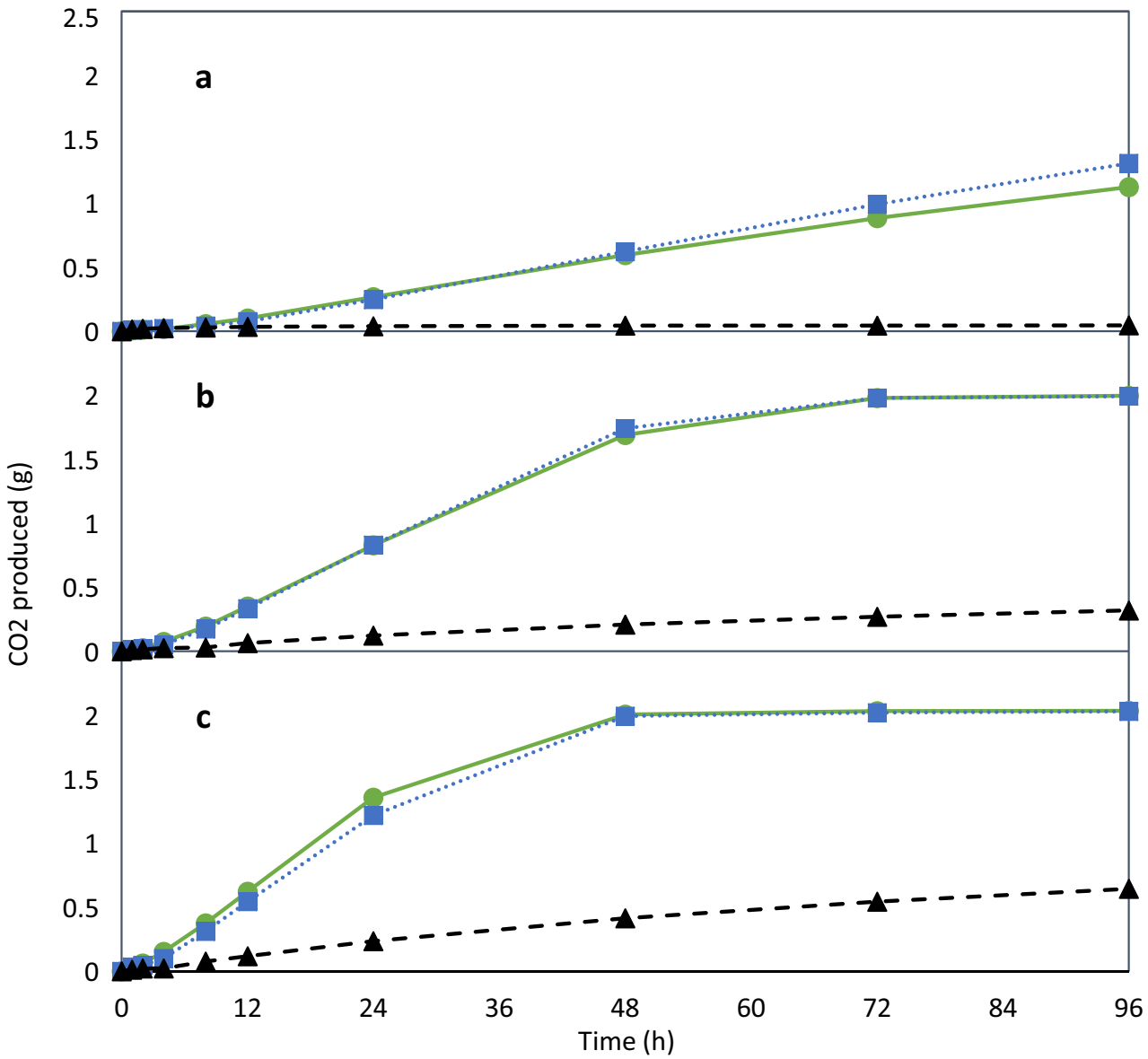


that the energy required for maintenance metabolism was increased at these conditions. These findings are in line with observations in previous studies on the effects of individual PDIs. It is generally accepted that yeast growth is inhibited by compounds derived from the pretreatment of lignocellulose, such as furfural [7, 23-26], HMF [27], acetic acid [26, 28, 29], and various phenolic compounds [27, 28, 30]. However, the results on the effects of these compounds on the ethanol formation rate are more divergent. On the one hand, it has been reported that high inhibitor concentrations lead to severe inhibition of cellular functions, and ultimately cell death, which has negative effects on product formation $[7,25,31]$. This was also observed in the fermentation experiments under the harsh condition in the present study, where product formation rates were consistently low and a net negative change in the number of viable cells was observed. On the other hand, there are reports that the yield of ethanol can increase despite the fact that the biomass yield is reduced at specific inhibitory conditions. Furfural [23] and acetic acid [6,29] have been shown to exhibit this effect. Acetic acid has even been observed to increase the ethanol formation rate within certain concentration ranges [29]. In the case of weak acids, this has been explained as the result of an increase in the energy required to maintain intracellular $\mathrm{pH}$ levels, thus diverting energy from cell growth [32], resulting in an increase in ethanol production without a corresponding increase in cell mass. This is in agreement with our observation that ethanol formation remained unchanged while cell growth decreased. A similar observation has been made for furfural, where the cell mass yield on ATP in batch fermentation with furfural was lower than in reference fermentations without furfural [23].

The findings of this study show that nutrient addition in fermentation inhibited by PDIs constitutes another factor affecting the balance between growth-associated and nongrowth-associated product formation. In the case of WPH at the mild condition, the addition of this nutrient source increased the specific rate of ethanol formation without any noticeable increase in cell growth, except at the highest level of WPH addition, where a more than threefold increase in the cell count was observed. It has been suggested that the lag phase commonly observed in the presence of inhibitors is caused by a genetic response resulting in a change in the cell physiology [33]. This kind of shift suggests that the synthesis of necessary enzymes is taking place in the cells. Taking this into consideration, a nitrogen shortage could limit the rate at which the cells can synthesize proteins to cope with the inhibitors. Therefore, an increase of the nutrient concentration would be expected to result in a higher inhibitor mitigation rate. However, this explanation alone does not account for the saturation in the product formation rate above $4 \mathrm{~g} / \mathrm{kg}$ of WPH.

A potential model explaining this saturation behavior is proposed. In this model, the amino acids are categorized into three categories based on the nutrient source and protein production: (I) amino acids not contained in the nutrient, (II) amino acids in limited supply, and (III) relatively abundant amino acids. It is then assumed that the production of proteins necessary for coping with the inhibitors would require that a specific mixture of amino acid was available to the synthesis pathways. As the free amino acid content of WPH was limited to a few types of amino acids, yeast protein production with WPH as the nutrient source would require the deamination of some of the amino acids for the synthesis of category I amino acids [20, 21, 34], regardless of the nutrient addition level. Additionally, the relative differences between the concentrations of individual amino acids will cause some amino acids to fall into category II, thus needing to be synthesized in order to achieve the appropriate amino acid mixture for protein production. A low level of nutrient addition will increase the available nitrogen, thus allowing for protein production in the cells without the need to resort to autophagy [35]. Protein production will, however, still be limited by the rate of amino acid deamination and the synthesis of category I and II amino acids [20]. Increasing the nutrient concentration reduces the need for synthesis of category II amino acids relative to category I. Above a certain concentration, the bottlenecking effect on the rate of synthesis of category I amino acids will be dominant, resulting in saturation of the stimulating effect of nutrient addition on the product formation rate. Furthermore, as YE had a more diverse combination of amino acids, this might explain why the saturation effect was observed for WPH but not for YE. At the highest level of nutrient addition, saturation of the product formation rate in the case of WPH coincided with a spike in the total cell count. This could indicate that the amount of available nitrogen was sufficiently high for the yeast to start prioritizing growth. However, it is surprising that this increase in cell mass was not accompanied by a corresponding increase in the product formation rate. This would have been expected from the increase in cellular energy consumption indicated by cell growth as described by Eq. 3. This implies that the addition of high levels of nutrient allowed a shift in the allocation of intracellular energy without affecting the product formation rate. However, the exact mechanism behind this observation has yet to be elucidated.

Two main observations can be made upon comparing the ethanol formation rates and cell growth in fermentation under the mild condition with that under the harsh condition. Firstly, in the case of the harsh condition, no clear increase was observed in the total cell count, compared to the reference case without nutrient addition, regardless of the nutrient type or nutrient concentration. However, a net loss of viable cells was observed. This indicates that above a certain inhibitor concentration, the mechanisms that allowed nutrient addition to increase cellular reproduction under the mild condition were inhibited. Previous studies have shown that high concentrations of PDIs can result in a complete arrest of growth and cell death $[7,23]$. Secondly, although no clear pattern was 
observed in cell growth under the harsh condition, ethanol production was still observed. Initially, the ethanol formation rate was the same, regardless of the nutrient type and concentration. However, in the case of $\mathrm{YE}$, a concentrationdependent increase in the product formation rate was observed $72 \mathrm{~h}$ into the fermentation. This implies that the high concentration of inhibitors under the harsh condition led to a lag phase that could not be shortened by nutrient addition. This is supported by the observation that the increase in the product formation rate occurs at about the same time, regardless of the nutrient concentration. A possible explanation of this could be that above a certain concentration, compounds present in the lignocellulosic hydrolysate inhibit the nitrogen assimilation metabolism. This is supported by a previous study by Ask et al. [36] where it was shown that genes related to amino acid transport were downregulated in the presence of HMF and furfural. Once the concentration of inhibitors has been sufficiently reduced, normal functions would be restored, and the effects of nutrients on the fermentation process would be similar to those observed under the mild condition.

\section{Conclusions}

The results presented in this paper clearly demonstrate that the addition of WPH during ethanol fermentation of a lignocellulosic hydrolysate helps mitigate the negative effects of PDIs on fermentation rates. However, on a $\mathrm{g} / \mathrm{g}$ basis, the mitigating effect was not as pronounced as that observed with YE. A saturation effect was also observed for WPH, which limited inhibitor mitigation above a certain concentration. The observed differences between the two nutrient sources were probably caused by limitations on the available amino acids and peptides due to differences in the compositions of WPH and YE. However, continued investigations on the use of WPH as a nutrient source are still of interest, as optimization of protein hydrolysis has the potential to yield promising results.

It was also shown that the inhibitors derived from the pretreatment of lignocellulose have distinct effects on the different functions of yeast at different concentrations. While cell growth was negatively affected in a linear fashion as the concentration of inhibitors was increased, the rate of fermentation was unaffected until a critical inhibitor concentration was reached. Furthermore, it was shown that both the nutrient type and the inhibitor concentration affect the balance between growth-associated and nongrowth-associated product formation.

While this study provides a proof of concept for the use of WPH as a nutrient source in lignocellulosic ethanol production, further investigations are still required to scale up the process to an industrial level. This includes further optimization of the wheat protein hydrolysis as well as a full techno-economic evaluation of the proposed design.

Supplementary Information The online version contains supplementary material available at https://doi.org/10.1007/s13399-021-01454-5.

Author contribution All authors contributed to the study conception and design. Michael Persson performed material preparation, data collection, and analysis. Michael Persson wrote the first draft of the manuscript, and all authors commented on the previous versions of the manuscript. All authors read and approved the manuscript.

Funding Open access funding provided by Lund University. Funding was provided by the Swedish Energy Agency.

Data availability Not applicable.

\section{Declarations}

Conflict of interest The authors declare no competing interests.

Code availability Not applicable.

Open Access This article is licensed under a Creative Commons Attribution 4.0 International License, which permits use, sharing, adaptation, distribution and reproduction in any medium or format, as long as you give appropriate credit to the original author(s) and the source, provide a link to the Creative Commons licence, and indicate if changes were made. The images or other third party material in this article are included in the article's Creative Commons licence, unless indicated otherwise in a credit line to the material. If material is not included in the article's Creative Commons licence and your intended use is not permitted by statutory regulation or exceeds the permitted use, you will need to obtain permission directly from the copyright holder. To view a copy of this licence, visit http://creativecommons.org/licenses/by/4.0/.

\section{References}

1. Murdock HE, Gibb D, André T, Appavou F, Brown A, Epp B, Kondev B, McCrone A, Musolino E, Ranalder L (2019) Renewables 2019 Global Status Report

2. Ajanovic A (2011) Biofuels versus food production: Does biofuels production increase food prices? Energy 36(4):2070-2076. https:// doi.org/10.1016/j.energy.2010.05.019

3. Azapagic A, Hall J, Heaton R, Kemp RJ, Ocone R, Shah N, Smith P, Swithenbank J, Chilvers A, Jeswani H (2017) The sustainability of liquid biofuels. Royal Academy of Engineering

4. Zhao X, Zhang L, Liu D (2012) Biomass recalcitrance. Part II: Fundamentals of different pre-treatments to increase the enzymatic digestibility of lignocellulose. Biofuels Bioprod Biorefin 6(5):561579. https://doi.org/10.1002/bbb.1350

5. Brethauer S, Studer MH (2015) Biochemical conversion processes of lignocellulosic biomass to fuels and chemicals-A review. CHIMIA Int J Chem 69(10):572-581

6. Larsson S, Palmqvist E, Hahn-Hägerdal B, Tengborg C, Stenberg K, Zacchi G, Nilvebrant N-O (1999) The generation of fermentation inhibitors during dilute acid hydrolysis of softwood. Enzym Microb Technol 24(3-4):151-159. https://doi.org/10.1016/S01410229(98)00101-X 
7. Navarro AR (1994) Effects of furfural on ethanol fermentation by Saccharomyces cerevisiae: Mathematical models. Curr Microbiol 29(2):87-90

8. Martínez-Moreno R, Morales P, Gonzalez R, Mas A, Beltran G (2012) Biomass production and alcoholic fermentation performance of Saccharomyces cerevisiae as a function of nitrogen source. FEMS Yeast Res 12(4):477-485

9. Mo F, Zhao H, Lei H, Zhao M (2013) Effects of nitrogen composition on fermentation performance of brewer's yeast and the absorption of peptides with different molecular weights. Appl Biochem Biotechnol 171(6):1339-1350. https://doi.org/10.1007/ s12010-013-0434-5

10. Thomas KC, Ingledew WM (1990) Fuel alcohol production: Effects of free amino nitrogen on fermentation of very-highgravity wheat mashes. Appl Environ Microbiol 56(7):2046-2050

11. Jones AM, Ingledew WM (1994) Fuel alcohol production: Appraisal of nitrogenous yeast foods for very high gravity wheat mash fermentation. Process Biochem 29(6):483-488. https://doi. org/10.1016/0032-9592(94)85017-8

12. Jørgensen $H$ (2009) Effect of nutrients on fermentation of pretreated wheat straw at very high dry matter content by Saccharomyces cerevisiae. Appl Biochem Biotechnol 153(1):44-57. https://doi. org/10.1007/s12010-008-8456-0

13. Persson M, Galbe M, Wallberg O (2020) A strategy for synergistic ethanol yield and improved production predictability through blending feedstocks. Biotechnol Biofuels 13(1):156. https://doi. org/10.1186/s13068-020-01791-Z

14. Joelsson E, Erdei B, Galbe M, Wallberg O (2016) Technoeconomic evaluation of integrated first- and second-generation ethanol production from grain and straw. Biotechnol Biofuels 9(1):116. https://doi.org/10.1186/s13068-015-0423-8

15. Palmqvist E, Hahn-Hägerdal B, Galbe M, Larsson M, Stenberg K, Szengyel Z, Tengborg C, Zacchi G (1996) Design and operation of a bench-scale process development unit for the production of ethanol from lignocellulosics. Bioresour Technol 58(2):171-179. https://doi.org/10.1016/S0960-8524(96)00096-X

16. Linde M, Jakobsson E-L, Galbe M, Zacchi G (2008) Steam pretreatment of dilute $\mathrm{H} 2 \mathrm{SO} 4$-impregnated wheat straw and SSF with low yeast and enzyme loadings for bioethanol production. Biomass Bioenergy 32(4):326-332. https://doi.org/10.1016/j.biombioe. 2007.09.013

17. Hirs CHW, Stein WH, Moore S (1954) The amino acid composition of ribonuclease. J Biol Chem 211(2):941-950. https://doi.org/ 10.1016/S0021-9258(18)71181-2

18. Erdei B, Galbe M, Zacchi G (2013) Simultaneous saccharification and co-fermentation of whole wheat in integrated ethanol production. Biomass Bioenergy 56:506-514

19. Russell I (2003) Understanding yeast fundamentals. Alcohol Textbook 4:531-537

20. Thorne RSW (1949) Nitrogen metabolism of yeast. A consideration of the mode of assimilation of amino acids. J Inst Brew 55(4):201222. https://doi.org/10.1002/j.2050-0416.1949.tb01492.x

21. Albers E, Larsson C, Lidén G, Niklasson C, Gustafsson L (1996) Influence of the nitrogen source on Saccharomyces cerevisiae anaerobic growth and product formation. Appl Environ Microbiol 62(9):3187-3195

22. Xu Y, Zhang M, Roozeboom K, Wang D (2018) Integrated bioethanol production to boost low-concentrated cellulosic ethanol without sacrificing ethanol yield. Bioresour Technol 250:299-305. https://doi.org/10.1016/j.biortech.2017.11.056

23. Palmqvist E, Almeida JS, Hahn-Hägerdal B (1999) Influence of furfural on anaerobic glycolytic kinetics of Saccharomyces cerevisiae in batch culture. Biotechnol Bioeng 62(4):447-454

24. Lin F-M, Qiao B, Yuan Y-J (2009) Comparative proteomic analysis of tolerance and adaptation of ethanologenic $<\mathrm{em}>$ Saccharomyces cerevisiae $</ \mathrm{em}>$ to furfural, a lignocellulosic inhibitory compound. Appl Environ Microbiol 75(11):3765-3776. https://doi.org/10. 1128/aem.02594-08

25. Banerjee N, Bhatnagar R, Viswanathan L (1981) Inhibition of glycolysis by furfural in Saccharomyces cerevisiae. Eur J Appl Microbiol Biotechnol 11(4):226-228

26. Li B-Z, Yuan Y-J (2010) Transcriptome shifts in response to furfural and acetic acid in Saccharomyces cerevisiae. Appl Microbiol Biotechnol 86(6):1915-1924. https://doi.org/10.1007/s00253-0102518-2

27. Taherzadeh MJ, Gustafsson L, Niklasson C, Lidén G (2000) Physiological effects of 5-hydroxymethylfurfural on Saccharomyces cerevisiae. Appl Microbiol Biotechnol 53(6): 701-708. https://doi.org/10.1007/s002530000328

28. Narendranath NV, Thomas KC, Ingledew WM (2001) Effects of acetic acid and lactic acid on the growth of Saccharomyces cerevisiae in a minimal medium. J Ind Microbiol Biotechnol 26(3):171-177. https://doi.org/10.1038/sj.jim.7000090

29. Taherzadeh MJ, Niklasson C, Lidén G (1997) Acetic acid-Friend or foe in anaerobic batch conversion of glucose to ethanol by Saccharomyces cerevisiae? Chem Eng Sci 52(15):2653-2659. https://doi.org/10.1016/S0009-2509(97)00080-8

30. Adeboye PT, Bettiga M, Olsson L (2014) The chemical nature of phenolic compounds determines their toxicity and induces distinct physiological responses in Saccharomyces cerevisiae in lignocellulose hydrolysates. AMB Express 4(1):46. https://doi.org/10.1186/ s13568-014-0046-7

31. Pfeifer PA, Bonn G, Bobleter O (1984) Influence of biomass degradation products on the fermentation of glucose to ethanol by Saccharomyces carlsbergensis W 34. Biotechnol Lett 6(8):541546. https://doi.org/10.1007/BF00139999

32. Viegas CA, Sá-Correia I (1991) Activation of plasma membrane ATPase of Saccharomyces cerevisiae by octanoic acid. Microbiology 137(3):645-651

33. Liu ZL (2006) Genomic adaptation of ethanologenic yeast to biomass conversion inhibitors. Appl Microbiol Biotechnol 73(1):2736. https://doi.org/10.1007/s00253-006-0567-3

34. Magasanik B, Kaiser CA (2002) Nitrogen regulation in Saccharomyces cerevisiae. Gene 290(1):1-18. https://doi.org/10. 1016/S0378-1119(02)00558-9

35. Onodera J, Ohsumi Y (2005) Autophagy is required for maintenance of amino acid levels and protein synthesis under nitrogen starvation*. J Biol Chem 280(36):31582-31586. https://doi.org/ 10.1074/jbc.M506736200

36. Ask M, Bettiga M, Mapelli V, Olsson L (2013) The influence of HMF and furfural on redox-balance and energy-state of xyloseutilizing Saccharomyces cerevisiae. Biotechnol Biofuels 6(1):22. https://doi.org/10.1186/1754-6834-6-22

Publisher's note Springer Nature remains neutral with regard to jurisdictional claims in published maps and institutional affiliations. 